\title{
Design and Computer Simulation of Automatically Controlled Hydromechanical System for Looped Wedge Wire Screen Elements Fabrication
}

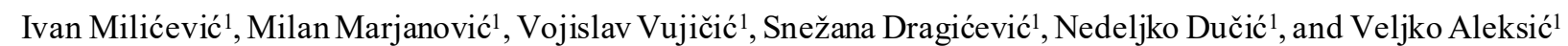

${ }^{1}$ University of Kragujevac, Faculty of Technical Sciences, Čačak, Serbia

The article presents a design of mechatronic system used for the production of wire elements used in looped wedge wire screen manufacturing. Details related to the design of the hydromechanical subsystem, the control subsystem, as well as the simulation of the operation process of the entire system are presented.

Keywords: Looped Wedge Wire Screens, Hydromechanical System, Control System, Simulation

\section{INTRODUCTION}

Looped Wedge Wire Screens [1-3] (Fig. 1) are produced in various forms and have a very wide application in following industries:

- Coal mining;

- Dewatering screens;

- Glass recycling screens;

- Gold mining;

- Petrochemical plants;

- Mineral and food processing;

- Sugar beet screens;

- Paper and pulp screens;

- Sand recovery/reclamation screens for foundries;

- Deep arch looped wedge wire is used for Coanda screens.
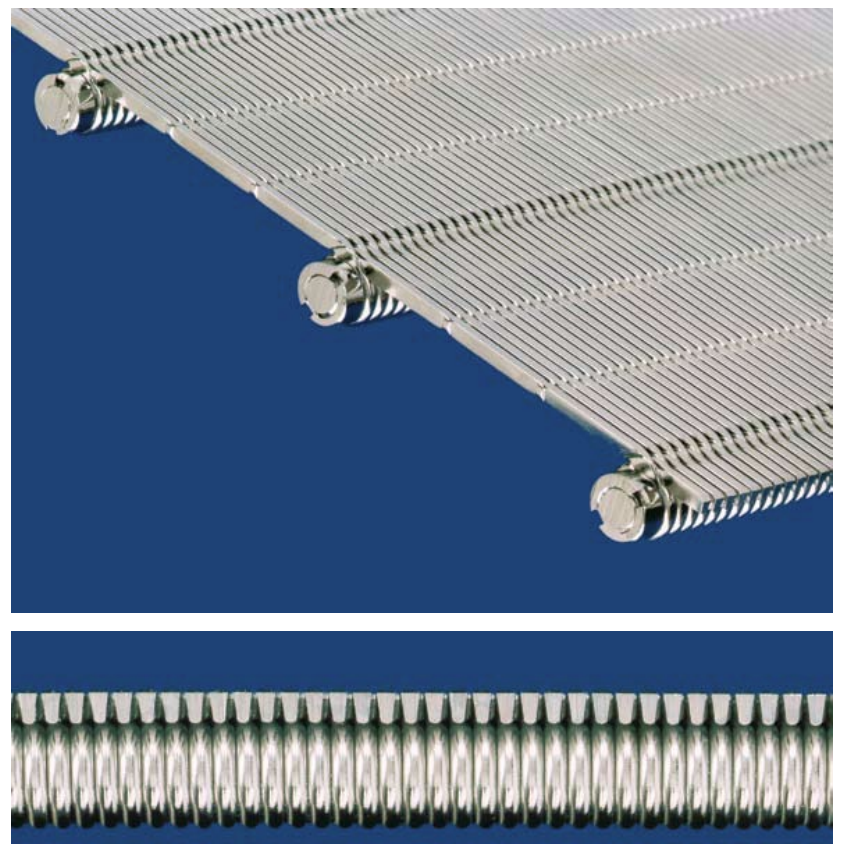

Figure 1: Looped Wedge Wire Screens

This type of wire screen is created by parallelly placing specially shaped wire profiles into the lattice frames and further connecting them with circular cross- section rods that are dragged through previou sly formed loops (Fig. 2). The gaps between such stacked wire profiles (Fig. 3) consequently ensures that the desire d gap between the trapezoidal wire profiles will be achieved. In addition, this procedure also enables choosing the shape and size of the profiles so these wire screens can be used for various applications. The profile trapezoidal shape prevents foreign particles from getting stuck and thus ensure that the wire screen does not clog.

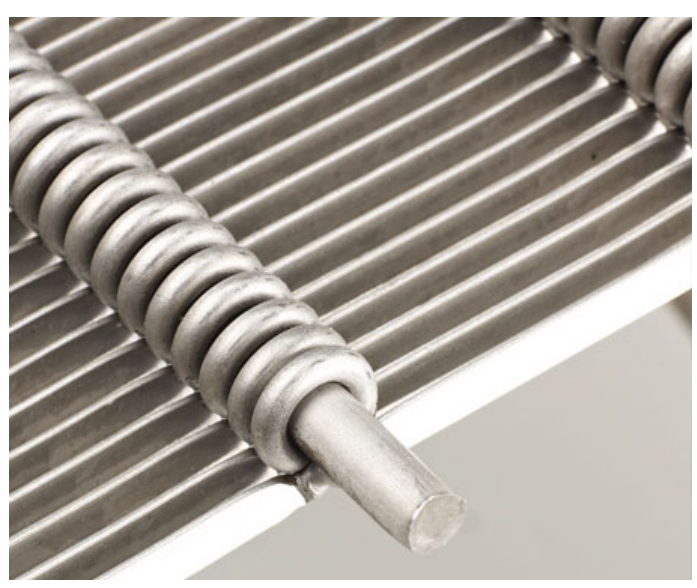

Figure 2: Stacking and connecting Wire profiles 


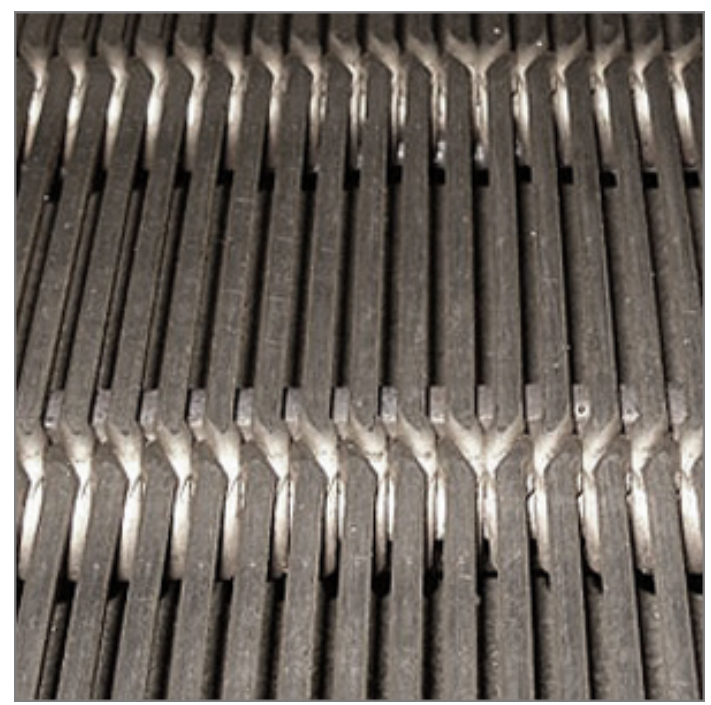

Figure 3: Wire screen with defined clearances

The elements required for the formation of wire screens are made of circular cross-section wire with the diameter $\emptyset 2 \div 5 \mathrm{~mm}$, usually made from high quality stainless steel in normalized state. The cross-section of elements used for further formatting is trapezoidal. The elements are then annularly bent at a certain step for further assembly into the final product (Fig. 1) with strict quality requirements (hardness, tight shape and dimension tolerances).

\section{DESIGN OF MECHATRONIC SYSTEM FOR THE WIRE PROFILES PRODUCTION}

2.1. Mechatronic system and mechanical elements moving analysis algorithm

Based on the provided technological operations that must be performed in order to produce the desired wire profile shown in Fig. 1-3, a design algorithm for the mechatronic system control was created (Fig. 4).

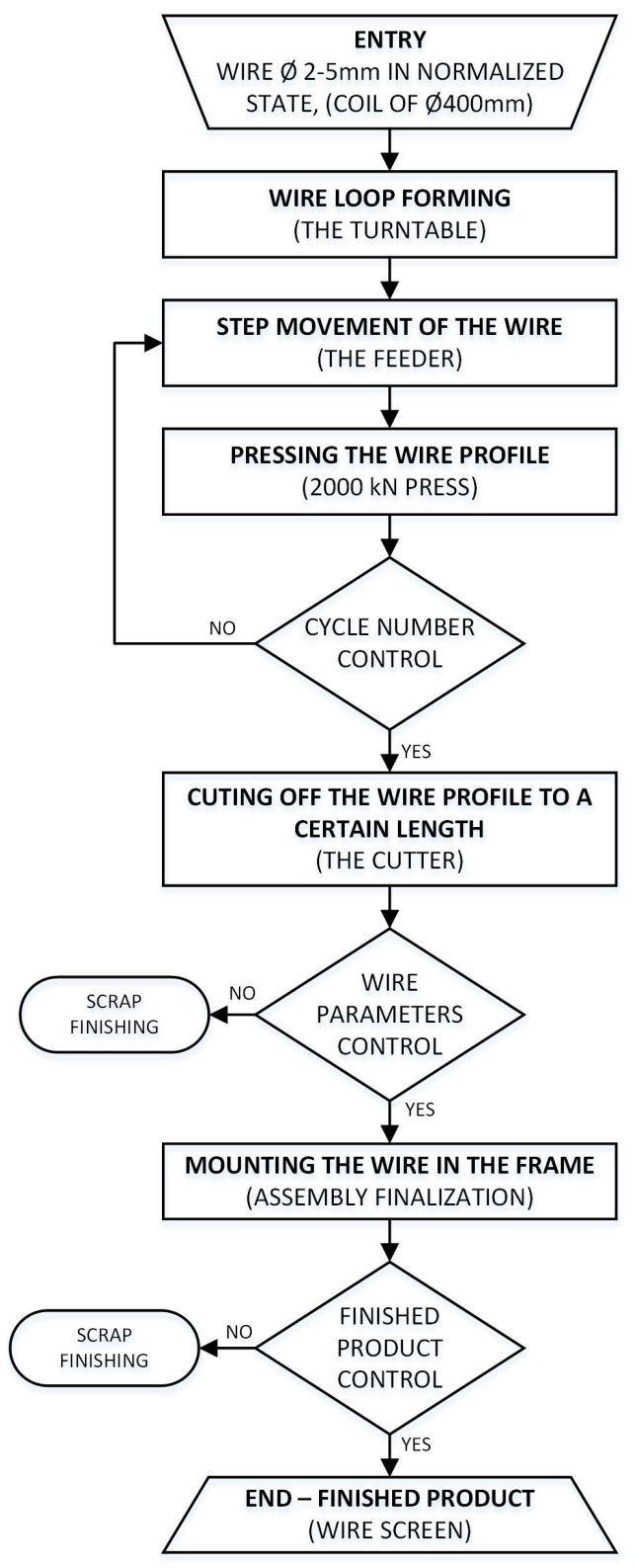

Figure 4: Algorithm for the looped wedge wire screen production

\subsection{Movement analysis of the mechanical subsystem} elements

It is envisaged that the movements of mechanical subsystem elements are performed by a hydraulic system consisting of two pumps and six hydraulic cylinders connected via electromagnetic distributors and PLC controlled valves. The hydraulic cylinders movement cyclogram (Fig. 7) is based on the necess ary movements for wire shaping, moving, pressing and cutting. All necessary movements are interdependent and are performed using 6 hydraulic cylinders.

In order to continuously bend the wire to the shape of a circular-helical loop it is necessary to achieve three interdependent movements (Fig. 5) with the help of three hydraulic cylinders:

- the first movement enables the wire bending around the special mandrels to form a helical loop - the turntable cylinder $(\mathrm{C} 4)$; 
- the second movement enables the movement of the spikes so that the loop can be formed and then released when finished - the feeder fixer cylinder (C1);

- the third movement allows the step movement of the wire (by the distance between two loops) - the feeder cylinder (C3).

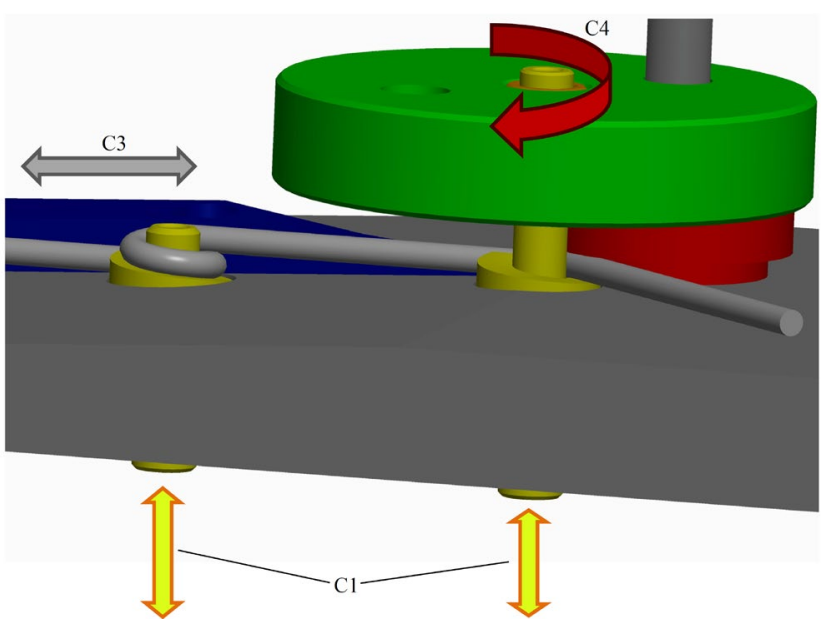

Figure 5: Movements that need to be controlled during the wire bending process

The part of the mechatronic system that compresses previously bent wire profiles performs a step movement of the wire by hydraulic cylinder C3 and two more interdependent movements by two hydraulic cylinders (Fig. 6):

- the fourth movement that enables the movement of the pressing tool moving part - the main press cylinder (C5);

- the fifth movement that enables the insertion of the mandrels into the tool in order to properly form the loop profile, and their further extraction from the tool in order to release the pressed loop - the tool retainer cylinder (C2).

Finally, after a certain number of cycles, it is necessary to cut off the obtained wire profile to a certain length. The sixth hydraulic cylinder moves the cutting tool - the cutter cylinder (C6).

All movements are interdependent, and some of them overlap in time. The whole cycle is predicted to last about $6 \mathrm{~s}$ [4].

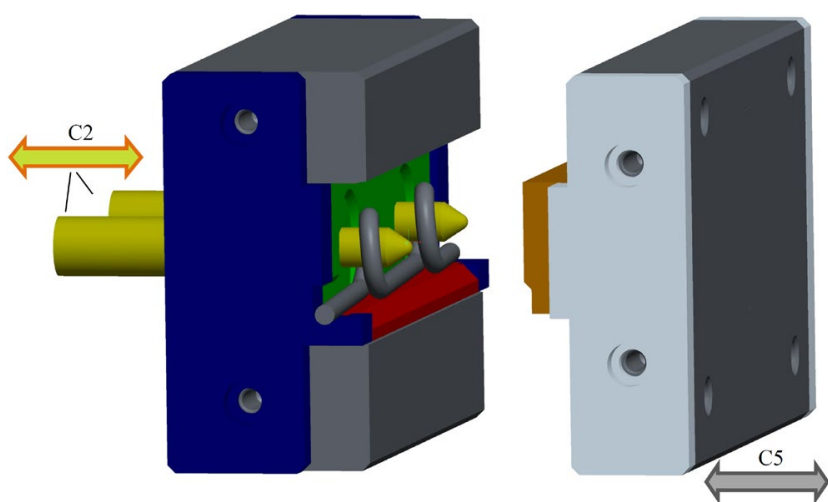

Figure 6: Movements that need to be controlled during the wire pressing process

Given the intensity of the calculated deformation force that should be achieved in the process of plastic deformation by compression to obtain the desired profile of stainless-steel wire with the diameter up to $5 \mathrm{~mm}$, it was calculated [5], [6] that the required pressure in the master cylinder which opens and closes the crimping tool (piston diameter $320 \mathrm{~mm}$ ) should be 240 bar. That is the maximum value for the $5 \mathrm{~mm}$ diameter wire [4]. It was taken into account that the process of plastic deformation by compression is performed by pressing only one loop in one step, although the tool is designed so that two loops could be pressed in each cycle (Fig. 4.30, 4.31). As the movement is performed for one (not two) steps each loop is pressed twice. This technological procedure achieves a constant step between two loops (which is necessary for connecting several wire profiles in the final product) and the calibration of the loop shape. Additionally, half the deformation force is required than when pressing two loops at the same time because the pressed surface is twice smaller.

To obtain the energy of the fluid required to drive the master cylinder, as well as all cylinders for auxiliary movements that do not overlap with the movement of the master cylinder piston, a piston pump with the variable flow of $0-25 \mathrm{l} / \mathrm{min}$ and 250 bar max. pressure at low flows is provided. In order to achieve all other necessary movements, a gear pump with a constant flow of $6.3 \mathrm{l} / \mathrm{min}$ and a maximum pressure of 160 bar is provided.

Given the required cycle period, it was calculated [4] that the maximum flow of the piston pump should be $25 \mathrm{l} / \mathrm{min}$. Taking into account the dimensions of the master cylinder and the working pressure that should be achieved, the flow values in individual cycle phases were also calculated and presented in the movement cyclogram (Fig. 5.6). 


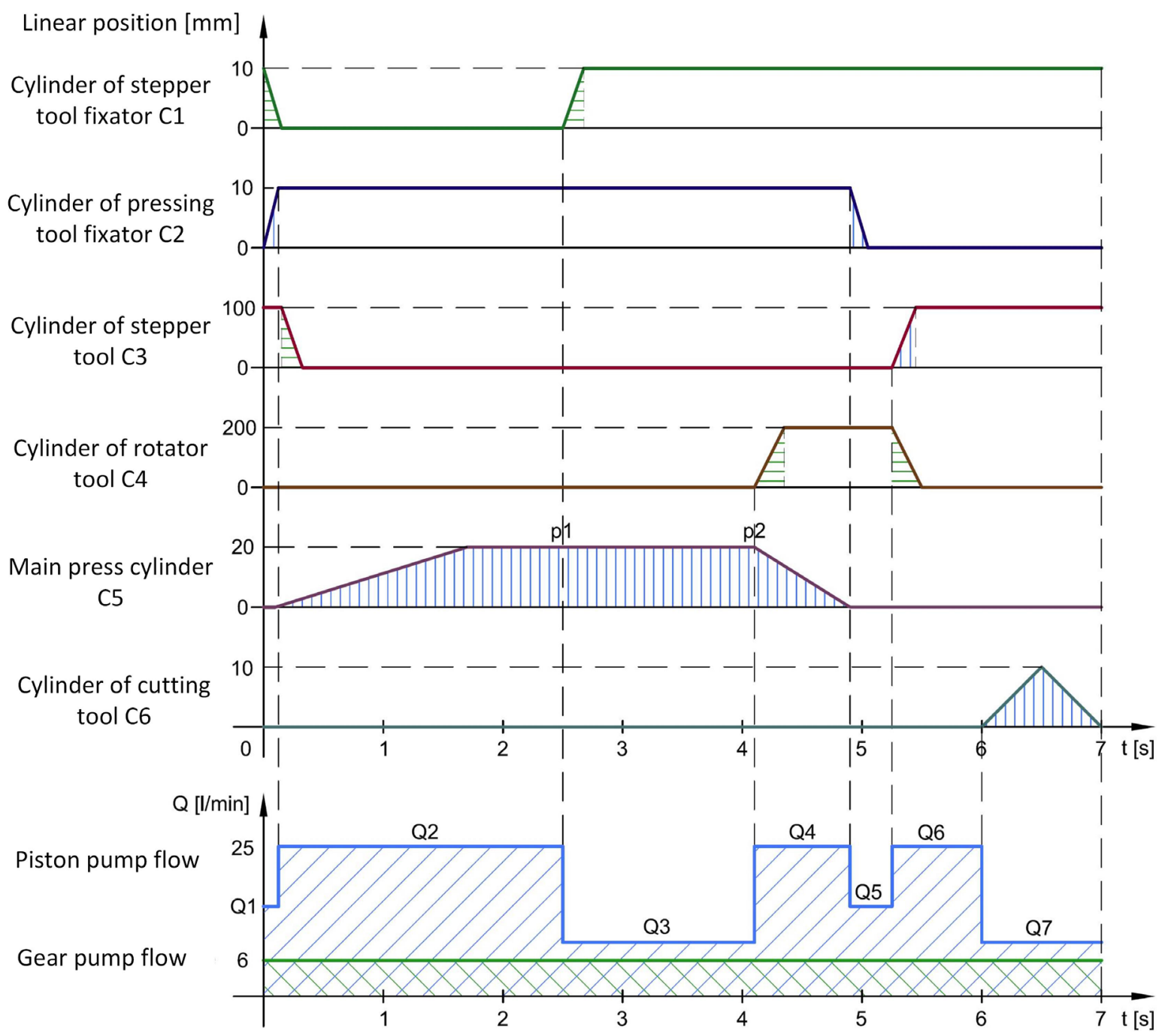

Figure 7: Movement cyclogram of hydraulic cylinders with defined pump flows

2.3. Electro-hydraulic scheme and the simulation of work process

Electro-hydraulic scheme of a mechatronic system for the wire profiles fabrication modeled in the Automation Studio [7] is shown in Fig. 8. All parameters of individual hydraulic and electrical components are set according to the designed values (dimensions and strokes of hydraulic cylinders, calculated flows, operating pressures, etc.) [4]. Since a trial version of the software was used, the variable flow pump was not available in the component database so it was modeled using multiple constant flow pumps with various flow intensities (Q1Q7). By selecting the appropriate hydraulic manifold ty pe $2 / 2$, we could engage one of the seven pumps with the adequate flow.

The Automation Studio [7] was also used for defining PLC's executable program for controlling the mechatronic system shown in the hydraulic diagram (Fig. 8). 


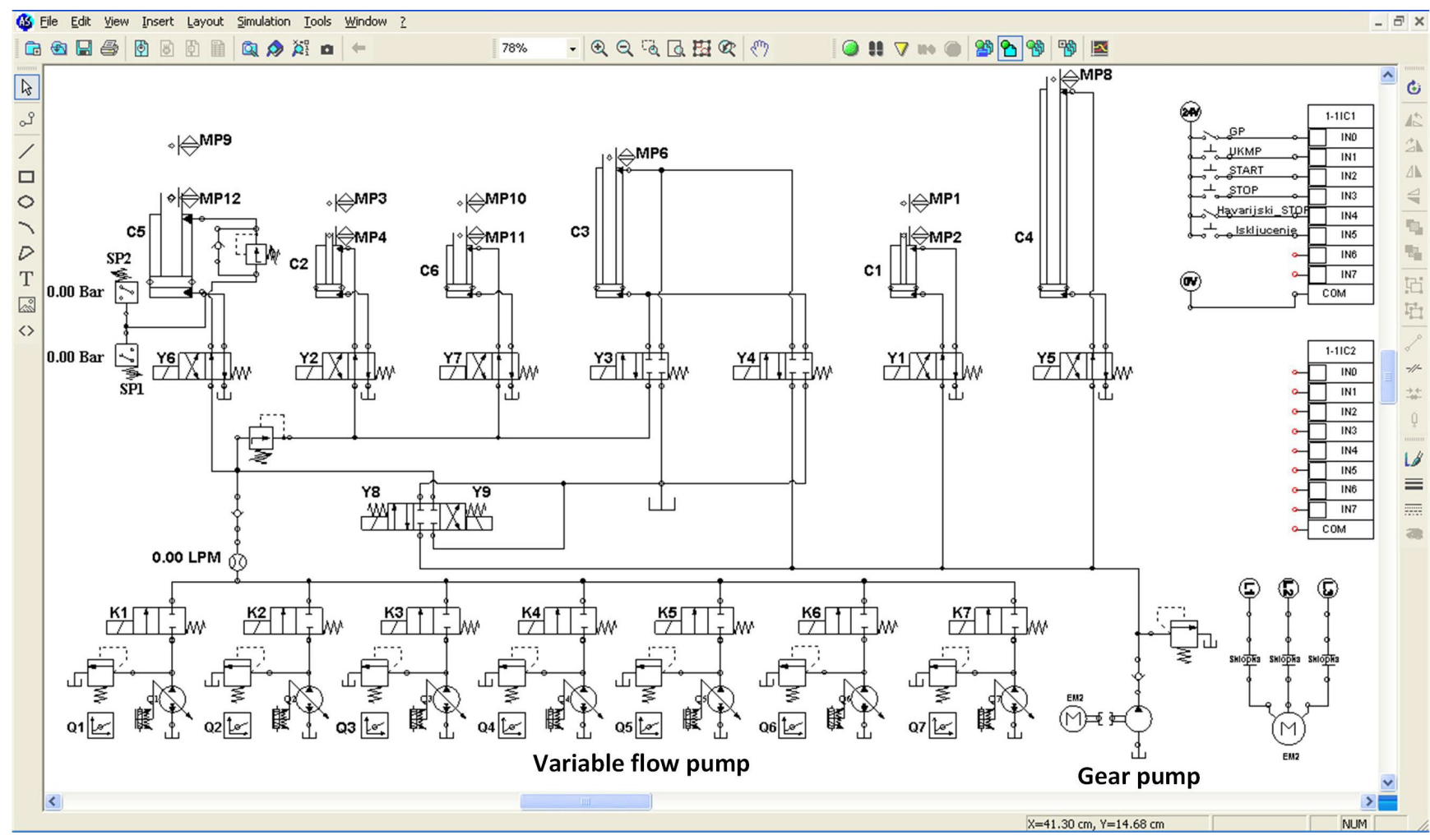

Figure 8: Hydraulic scheme of the mechatronic system

The input signals for the PLC controller are provided by the inductive microswitches marked MP and by the ON/OFF switches at the pump motor.

After the main GP switch is turned $\mathrm{ON}$ and the UKMP button is pressed, both pump motors and the Y8 solenoid valve are switched on and the piston pump runs at Q1 flow.

The START button enables the operation state. Solenoid valves Y3 and Y9 are switched on and the Y8 valve is switched off. The pumps move the cylinders at the starting position.

In the next operation, the solenoid valves Y3 and Y9 are switched off, and the Y1 and Y2 valves are switched on, and the cycle begins. The feeder retainer cylinder is retracted (in order to release the loop bent in the previous cycle so that the feeder cylinder can return), and the tool retainer cylinder is pulled out (thorns are retracted into the loop openings so that the process of plastic deformation by compression can begin in the next step).

When the feeder retainer cylinder is retracted and the tool retainer cylinder is pulled out, the solenoid valves Y4 and Y6 are switched on at the same time so that the feeder cylinder and the piston of the master cylinder start moving at the maximum flow Q2 until pressure $p_{1}$ is reached (monitored at the pressure sensor SP1), which combined with the signal from the limiter microswitch MP6 (retracted feeder cylinder) is a condition for disconnecting the solenoid valves Y1 and Y4 and pulling out the feeder retainer. At the end of the stroke the limiter microswitch MP1 is activated so the compression process is completed (appropriate pressure $p_{2}$ is received from the pressure sensor SP2), the solenoid valve Y 5 is turned on and the rotator cylinder pull out begins. When pressure $p_{I}$ is reached, the process of compressing the wire in the tool with the piston pump Q3 flow begins so that the defined working pressure $p_{2}$ can be achieved.

After reaching the pressure $p_{2}$ (signal monitored at the pressure transmitter SP2), the solenoid valve Y6 is switched off and the piston of the press master cylinder starts moving, now with the maximum flow of the piston pump Q4, due to faster opening of the pressing tool. After opening the tool and receiving a signal from the limiter microswitch MP12, the solenoid valve Y2 is switched off and the retraction of the tool fixator begins with Q5 flow. When a signal from the MP4 limiter microswitch (tool retainer retraction completed) is received, along with fulfilling the complete rotation cylinder extraction condition the new loop is formed (signal from MP7 limiter microswitch received), the solenoid valve Y5 is switched off and the Y3 valve is switched on - the torque cylinder retraction and the feeder cylinder pull out begins at the same time by the piston pump Q6 flow. At the end of the feeder cylinder stroke, the solenoid valve Y3 is switched off.

The new cycle automatically starts by switching on the solenoid valves Y1 and Y2 (the initial positions of the hydraulic cylinders are reached).

When a number of cycles defined by the PLC is performed, the solenoid valve $\mathrm{Y} 7$ is turned on at the flow of the piston pump Q7, the cutter cylinder is pulled out and the formed wire profile is cut off. After that, the solenoid valve $\mathrm{Y} 7$ is switched off, the counter is reset to the preset number of cycles and the cutter cylinder is inserted, after which a new cycle can start by switching on the solenoid valves Y1 and Y2 with Q1 flow.

The program also envisages various emergency situations. By pressing the STOP button during operation, all hydraulic cylinders are first reset, and only then are all solenoid valves and pump motors switched off. 
Pressing the EMERGENCY STOP button immediately stops the machine and all solenoid valves and pump motors are switched off. After the fault has been rectified, the system is restarted by pressing the UKMP button and then the START button.

\section{THE ANALYSIS OF SIMULATION RESULTS}

The operating parameters of individual components (position, speed, acceleration, pressure, etc.) can be continuously monitored as a function of time during the system simulation, whereby data can be transferred to a text file that can be later used in any database software.

System testing was performed according to the designed system parameters (operating pressures, hydraulic pump flows, dimensions of hydraulic cylinders piston diameters, maximum strokes, etc.), and the simulation results were satisfactory.
The cyclogram of the movement of hydraulic cylinders obtained by simulating the operation of the system is presented in Fig. 9. The cycle time is about $6,2 \mathrm{~s}$. The deviation from the estimated cycle time that was the basis for calculating system components is:

$$
\Delta t=\frac{t_{2}-t_{1}}{t_{1}}=\frac{6,2-6}{6}=0,033=3,3 \%
$$

It should be emphasized that the simulation was performed with the maximum possible feeder cylinder piston stroke, which is generally shorter in the actual process and certainly had to have an impact on the obtained slightly longer cycle time. The feeder cylinder piston stroke is determined by the cycle step, i.e. the distance between two loops, and is defined by the position of the limiter microswitch MP6 (Fig. 8).

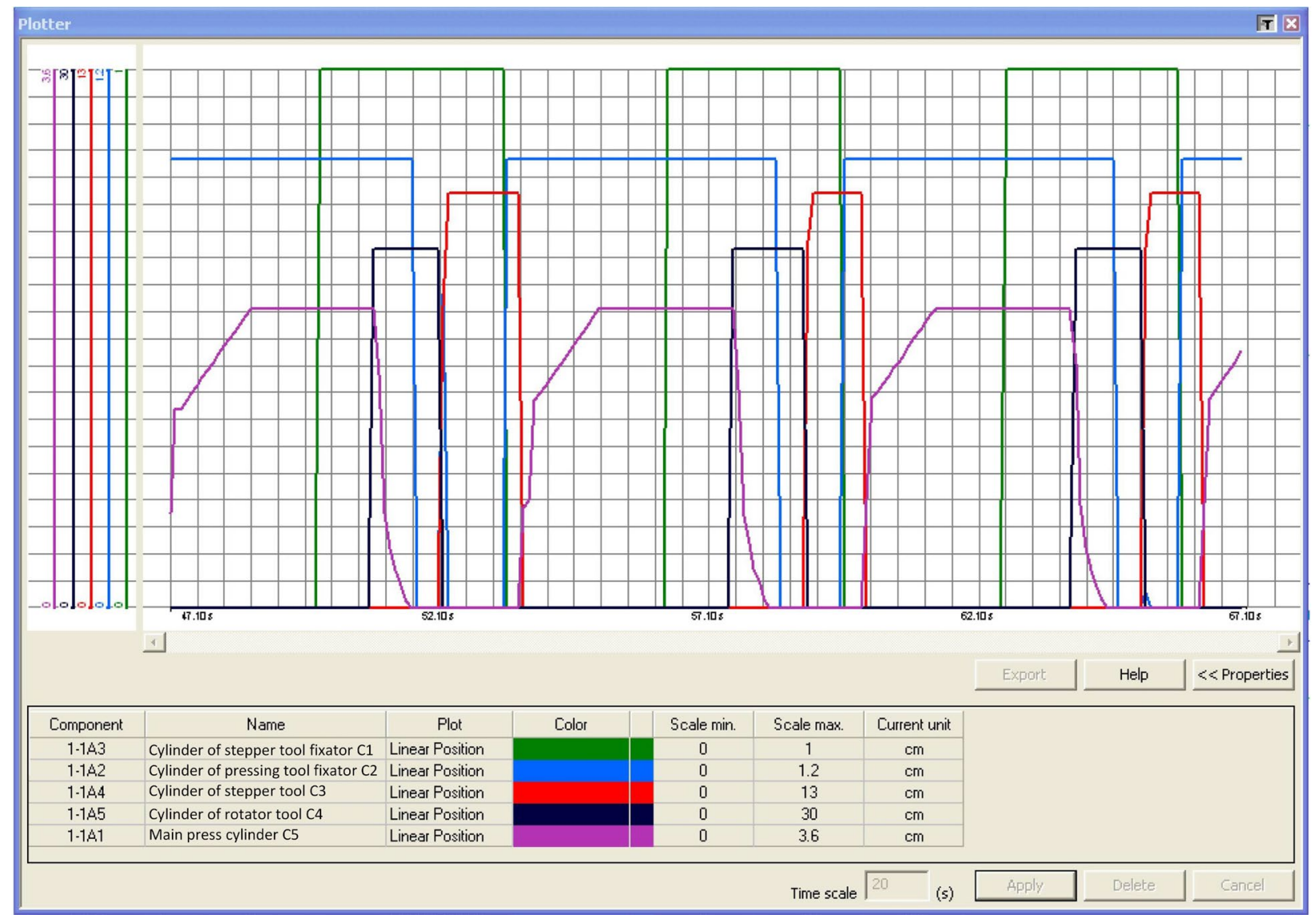

Figure 9: Movement cyclogram of hydraulic cylinders at maximum piston pump flow of $25 \mathrm{l} / \mathrm{min}$

The impact of changing any parameter of any component on certain system characteristics can be easily monitored by simulating system operations and monitoring the desired parameters.

For example, Fig. 10 shows a movement cyclogram of the hydraulic cylinders obtained at a maximum piston pump flow of $201 / \mathrm{min}$, with an unchanged ratio of other flows and other parameters. The cycle time was about $7,4 \mathrm{~s}$, which is significantly more than the required $6 \mathrm{~s}$.

The pressure variation of the main cylinder of the press, on the piston side and on the connecting rod side is presented in Fig. 11, as well as the change in position as a function of time, which also coincides with the projected values. 


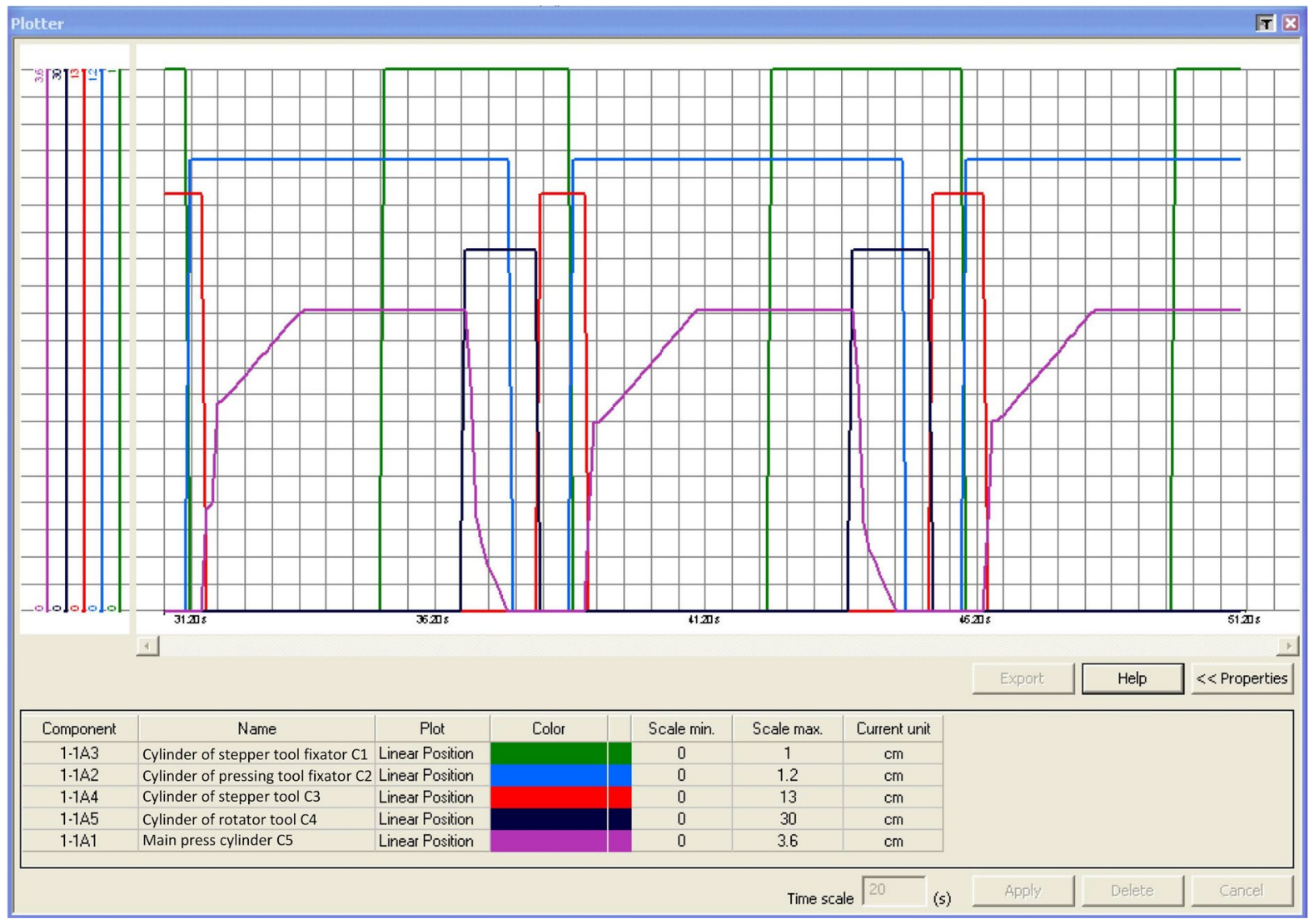

Figure 10: Movement cyclogram of hydraulic cylinders at maximum piston pump flow of $20 \mathrm{l} / \mathrm{min}$

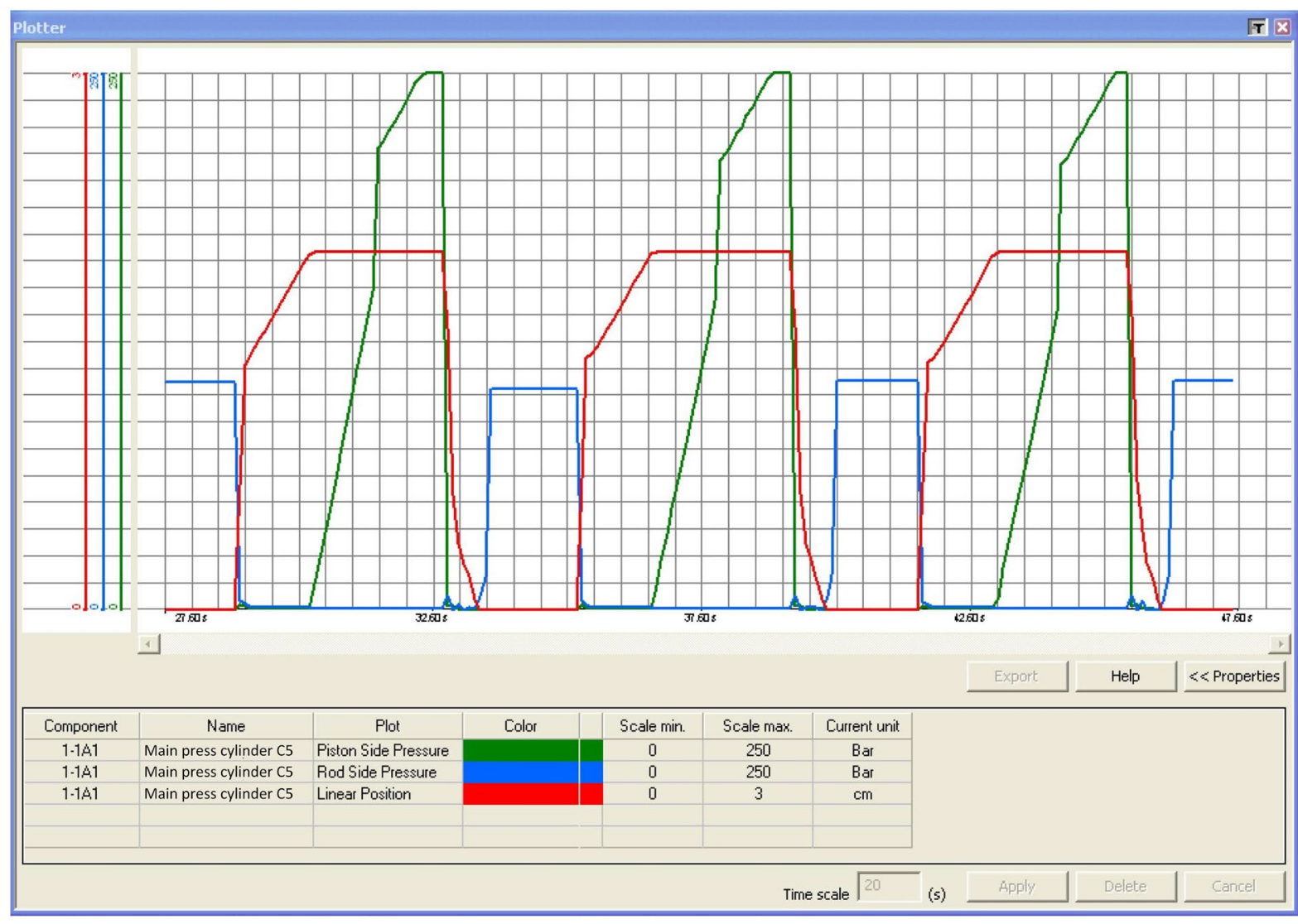

Figure 11: Changing the pressure and position in the press master cylinder

\section{CONCLUSION}

The analysis of the movements necessary for the realization of the production cycle was performed. The movement cyclogram of the executive elements of the system is defined. The electro-hydraulic system with appropriate sensors is selected as the drive system for the realization of the necessary movements under certain conditions and controlled by the PLC program. 
The optimization of selected electro-hydraulic components was performed by analyzing individual parameters in order to obtain the required characteristics of the system.

Complete simulation of the system (both in normal operating conditions and in the irregular events) made it easier to observe the process as a whole, and identify and correct any shortcomings of the PLC program before installing it in considered mechatronic system.

\section{ACKNOWLEDGEMENTS}

This study was supported by the Ministry of Education, Science and Technological Development of the Republic of Serbia, and these results are parts of the Grant No. 451-03-9/2021-14/200132 with University of Kragujevac - Faculty of Technical Sciences in Čačak.

\section{REFERENCES}

[1] https://www.heinlehmann.de/en/products/wedge-wirescreens/rima-corima

[2] Welded Wedge Wire Screens Looped Wedge Wire $\underline{\text { Screens } \mid \text { Harpscreen }}$

[3] Looped Wedge Wire Screens |Curved Screens | Screen $\underline{\text { Systems }}$

[4] Milićević, I.: "Sinteza mehatroničkog sistema za izradu specijalno oblikovanih žičanih profila", Doktorska disertacija, Fakultet tehničkih nauka, Čačak, (Serbia), (2013)
[5] A. K. Gupta, S. K. Arora, J. R. Westcott: "Industrial Automation and Robotics", Mercury Learning and Information LLC, (USA), (2017)

[6] P. Chapple: Principles of Hydraulic System Design, Coxmoor Publishing Company, Oxford, (UK), (2003)

[7] https://www.famictech.com/en/Products/AutomationStudio/Educational-Edition

\section{Dizajn i kompjuterska simulacija automatski kontrolisanog hidromehaničkog sistema za proizvodnju elemenata sita sa klinastim žicom}

Ivan Milićević1 ${ }^{\text {, Milan Marjanović }}{ }^{1}$, Vojislav Vujičić ${ }^{1}$, Snežana Dragićević ${ }^{1}$, Nedeljko Dučić ${ }^{1}$, Veljko Aleksić ${ }^{1}$

${ }^{1}$ Univerzitet u Kragujevcu, Fakultet tehničkih nauka, Čačak, Srbija

U članku je prikazan dizajn mehatroničkog sistema koji se koristi za proizvodnju žičanih elemenata koji se koriste u proizvodnji klinastih žičanih sita. Prikazani su detalji vezani za projektovanje hidromehaničkog podsistema, upravljačkog podsistema, kao i simulaciju procesa rada celog sistema.

Ključne reči: Looped Vedge Vire Screens, Hidromehanički sistem, Sistem upravljanja, Simulacija 